\title{
Dubinin-Astakhov Model for Acetylene Adsorption on Metal- Organic Frameworks
}

\author{
Peifu Cheng and Yun Hang $\mathrm{Hu}^{*}$
}

Department of Materials Science and Engineering, Michigan Technological University, 1400 Townsend Drive, Houghton, MI 49931-1295, USA.

yunhangh@mtu.edu

\begin{abstract}
Acetylene $\left(\mathrm{C}_{2} \mathrm{H}_{2}\right)$ is explosive at a pressure above 29 psi, causing a safety issue for its storage and applications. $\mathrm{C}_{2} \mathrm{H}_{2}$ adsorption on metal-organic frameworks (MOFs) has been explored to solve the issue. However, a suitable isotherm equation for $\mathrm{C}_{2} \mathrm{H}_{2}$ adsorption on various MOFs has not been found. In this paper, it was demonstrated that Dubinin-Astakhov equation can be exploited as a general isotherm model to depict $\mathrm{C}_{2} \mathrm{H}_{2}$ adsorption on MOF-5, ZIF-8, HKUST-1, and MIL-53. In contrast, commonly used Langmuir and BET models exhibited their inapplicability for $\mathrm{C}_{2} \mathrm{H}_{2}$ adsorption on those MOFs.
\end{abstract}

\section{Keywords}

$\mathrm{C}_{2} \mathrm{H}_{2} \cdot$ adsorption $\cdot$ Dubinin-Astakhov equation $\cdot$ metal-organic frameworks

*To whom correspondence should be addressed. Phone: 906-4872261, Email: vunhangh@mtu.edu 


\section{Introduction}

Acetylene $\left(\mathrm{C}_{2} \mathrm{H}_{2}\right)$, which is the simplest unsaturated hydrocarbon with a triple bond [1], is an energy-rich fuel for oxy-acetylene welding and metal cutting and an important chemical building block for catalytic synthesis of fine-chemicals [2,3]. However, acetylene is explosive at pressures above 29 psi, which constitutes a critical safety issue $[3,4]$. To solve this issue, acetylene is usually dissolved in acetone or dimethylformamide (DMF) and transported by gas cylinders with a porous material (Agamassan). Unfortunately, this storage system has low storage capacity and low gas withdrawal rate [1]. Although microporous materials (such as zeolites, molecular sieves, and activated carbon) are also employed to purify and store acetylene, they possess a low uptake capacity and a poor selectivity and catalyze acetylene polymerization [5-9].

As a new type of porous materials, metal-organic frameworks (MOFs) have attracted much attention for gas separation and storage due to their low density structures, ultra-high surface areas, and tunable frameworks [10-22]. MOFs have been explored to enhance acetylene uptake capacity, improve its selectivity, and inhibit its polymerization [1,4,23-36]. Furthermore, various adsorption models (such as Dual-site Langmuir equation [37], Langmuir equation [33], Virial expression [25], and so on $[27,31,35,36,38])$ were exploited for acetylene adsorption isotherms. However, none of them can well depict acetylene adsorption on various MOFs. Thus it is necessary to find an equation as a general model for acetylene adsorption on various MOFs.

As early as 1947, Dubinin and Radushkevich proposed Dubinin-Radushkevich 
equation (DR equation) [39] incorporating Polanyi's Potential Theory [40] with the affinity coefficient to describe physical adsorption on heterogeneous surfaces. Based on DR equation, Dubinin developed the theory of volume filling of micropores (TVFM) [41], which made a considerable contribution in classification of microporous adsorbents and understanding the differences between physical adsorptions on porous and nonporous adsorbents. DA equation (Eq. 1), which is a more generalized version, can linearize gas adsorption on a wider variety of materials $[42,43]$.

$$
\theta=\exp \left[-\left(\frac{A}{E}\right)^{n}\right]
$$

where $A=-R T \ln \left(p / p_{0}\right)$ and is the differential molar work of adsorption, $E$ is the characteristic energy of adsorption, and $n$ is the Astakhov exponent. Though DA equation is semi-empirical in nature, it can be used to obtain information about micropore structures from a single adsorption isotherm [44]. Furthermore, Chen and Yang derived Dubinin-Astakhov equation from statistical mechanical principles [45]. A unique advantage of DA equation over others is that the Dubinin-Astakhov parameters are independent on temperature [46]. DA equation was employed to evaluate benzene and cyclohexane adsorption on steam gasified humic acid chars from brown coal [47]. We found that Dubinin-Astakhov equation could well describe $\mathrm{CO}_{2}$ adsorption on SWCNTs [48]. In this paper, we demonstrated that Dubinin-Astakhov equation can be used as a general model for acetylene adsorption on metal-organic frameworks (MOFs). This finding would be important for $\mathrm{C}_{2} \mathrm{H}_{2}$ storage in and its catalytic conversion on MOFs. 


\section{Experimental Section}

\subsection{Preparation of samples}

MOF-5 was synthesized via the approach developed by Yaghi and his co-workers [49], and briefly described as follows: $0.45 \mathrm{~g} \mathrm{Zn}\left(\mathrm{NO}_{3}\right)_{2} \cdot 6 \mathrm{H}_{2} \mathrm{O}$ and $0.083 \mathrm{~g}$ terephthalic acid were dissolved in a $100 \mathrm{ml}$ Pyrex media bottle with $49 \mathrm{ml}$ of dimethylformamide (DMF) and $1 \mathrm{ml}$ distilled $\mathrm{H}_{2} \mathrm{O}$, and sealed by a Teflon lined lid. The obtained mixture was heated at $100{ }^{\circ} \mathrm{C}$ for $7 \mathrm{~h}$ to yield large crystals. The bottle was then cooled to room temperature and transferred to an argon-filled glove bag. All subsequent manipulations were performed in this glove bag under argon atmosphere using oven-dried glassware and anhydrous solvents. The obtained solid was washed six times with anhydrous DMF and anhydrous $\mathrm{CH}_{2} \mathrm{Cl}_{2}$ (each time soaking the solid for $8 \mathrm{~h}$ ), respectively. Finally, after filtering the mixture, the remained product was heated at $115^{\circ} \mathrm{C}$ for $24 \mathrm{~h}$ to yield $\mathrm{Zn}_{4} \mathrm{O}(\mathrm{BDC})_{3}$ as colorless cube-shaped crystals.

ZIF-8, HKUST-1, and MIL-53 (Al) were purchased from Sigma-Aldrich.

\subsection{Standard measurements of surface areas}

$\mathrm{N}_{2}$ adsorption on MOF-5, ZIF-8, HKUST-1, or MIL-53 was measured at $77 \mathrm{~K}$ using Micromeritics ASAP 2000 sorptometer. The samples were degassed under vacuum at $120^{\circ} \mathrm{C}$ for 12 hours before the measurement. The surface areas from the $\mathrm{N}_{2}$ adsorption were calculated by Brunauer-Emmett-Teller (BET) model [50].

\section{3. $\mathrm{C}_{2} \mathrm{H}_{2}$ adsorption measurements}


$\mathrm{C}_{2} \mathrm{H}_{2}$ adsorption isotherms on MOF-5, ZIF-8, HKUST-1, and MIL-53 were measured by volumetric method [19] at a selected temperature (273 K or $298 \mathrm{~K}$ ) as follows: $200 \mathrm{mg}$ of samples were loaded into a reactor and degassed under vacuum at $100{ }^{\circ} \mathrm{C}$ for $12 \mathrm{~h}$. Then, $\mathrm{C}_{2} \mathrm{H}_{2}$ was introduced into the reactor for adsorption. The $\mathrm{C}_{2} \mathrm{H}_{2}$ pressure change during adsorption and desorption were monitored with a digital pressure gauge (Accu-Cal Plus 75514-29B55 with a precision of 1 Torr), generating the adsorption/desorption isotherm of pressure $v s$. amount of adsorbed/desorbed $\mathrm{C}_{2} \mathrm{H}_{2}$.

\section{Results and Discussion}

3.1. Applicability evaluation of Langmuir, BET, and Dubinin-Astakhov models for acetylene adsorption

Acetylene adsorption on MOF-5, ZIF-8, HKUST-1, and MIL-53 was carried out at 273 and $298 \mathrm{~K}$, generating adsorption isotherms (Fig. 1a, 2a, 3a, and 4a). Models of Langmuir (Eq. 2), BET (Eq. 3), and Dubinin-Astakhov (Eq. 4) were employed to fit those isotherms.

$$
\begin{gathered}
\frac{\left(p / p_{0}\right)}{V}=\frac{1}{V_{0} b}+\frac{1}{V_{0}}\left(\frac{p}{p_{0}}\right) \\
\frac{\left(\frac{p}{p_{0}}\right)}{\left(1-\frac{p}{p_{0}}\right) V}=\frac{1}{V_{0} c}+\left(\frac{c-1}{V_{0} c}\right)\left(\frac{p}{p_{0}}\right) \\
\ln V=\ln V_{0}-\left(\frac{R T}{E}\right)^{n}\left[\ln \left(\frac{p_{0}}{p}\right)\right]^{n}
\end{gathered}
$$

where $V, V_{0}, P, P_{0}, R, T, E, n, b$, and $c$ are the total volume adsorbed, the monolayer capacity, the equilibrium pressure, the saturation vapor pressure of the gas, the ideal gas constant, temperature, the characteristic energy of adsorption, the Astakhov exponent, the adsorption equilibrium constant, and the BET constant, respectively. As shown in 
Fig. 1-4, one can see that Langmuir and BET equations provide a good-fitting line for $\mathrm{C}_{2} \mathrm{H}_{2}$ adsorption isotherms on HKUST-1 and MIL-53, but not for those on MOF-5 and ZIF-8. In contrast, Dubinin-Astakhov model can well depict all $\mathrm{C}_{2} \mathrm{H}_{2}$ adsorption isotherms on MOF-5, ZIF-8, HKUST-1 and MIL-53 (Fig. 1-4).

It is well-known that the standard method for surface area measurements is $\mathrm{N}_{2}$ adsorption at its liquid temperature $(77 \mathrm{~K})$ with BET model. Although BET model is generally unsuitable for the surface area estimation of microporous materials, Monte Carlo simulations revealed that BET surface areas of MOFs calculated from the simulated $\mathrm{N}_{2}$ isotherms at $77 \mathrm{~K}$ agree very well with the accessible surface areas calculated directly from the crystal structures in a geometric fashion [51]. This provides a validation that the BET theory can be used for $\mathrm{N}_{2}$ adsorption at its liquid temperature to obtain reliable surface areas of MOFs. The surface areas, which were obtained with the standard $\mathrm{N}_{2}$ adsorption approach, are 3450, 1505, 1998, and $1005 \mathrm{~m}^{2} / \mathrm{g}$ for MOF-5, ZIF-8, HKUST-1, and MIL-53, respectively (Table 1). Those accurate surface areas will be compared with those obtained from $\mathrm{C}_{2} \mathrm{H}_{2}$ adsorption isotherms at 273 and $298 \mathrm{~K}$ using Langmuir, BET, and Dubinin-Astakhov equations. This can allow us to further evaluate the applicability of those models for $\mathrm{C}_{2} \mathrm{H}_{2}$ adsorption on MOFs.

The monolayer capacities $\left(V_{0}\right)$ of $\mathrm{C}_{2} \mathrm{H}_{2}$ on MOFs, which were obtained by fitting isotherms with Langmuir, BET, and Dubinin-Astakhov models (Table 1), were exploited to calculate surface areas of MOFs with Eq. 5.

$$
S A\left(\mathrm{~m}^{2} / \mathrm{g}\right)=\frac{6.022 \times 10^{23} \sigma V_{0}}{22414 \mathrm{~cm}^{3} \times 10^{18} \mathrm{~nm}^{2} / \mathrm{m}^{2}}
$$

where $S A$ is the calculated surface area of the adsorbent (MOFs), $V_{0}$ is the monolayer 
capacity, and $\sigma$ is the cross-sectional area of the gas $\left(\mathrm{C}_{2} \mathrm{H}_{2}\right)$ that was calculated with Eq.

6.

$$
\sigma=f\left(\frac{M}{\rho N_{a}}\right)^{2 / 3}
$$

where $f$ is the packing factor (for hexagonal-close-packed, then f equals 1.091), $\rho$ the density of liquid adsorbate $\left(\mathrm{C}_{2} \mathrm{H}_{2}\right), M$ the molar mass of the adsorbate $\left(\mathrm{C}_{2} \mathrm{H}_{2}\right)$, and $N_{\mathrm{a}}$ Avogadro's number. At 273 and $298 \mathrm{~K}$, the densities of liquid $\mathrm{C}_{2} \mathrm{H}_{2}$ are 0.451 and 0.406 $\mathrm{g} / \mathrm{cm}^{3}$ [52] and thus the cross-sectional areas of $\mathrm{C}_{2} \mathrm{H}_{2}$ are 0.2283 and $0.2449 \mathrm{~nm}^{2}$, respectively. As shown in Table 1, the application of Dubinin-Astakhov model to $\mathrm{C}_{2} \mathrm{H}_{2}$ adsorption isotherms (at 273 and $298 \mathrm{~K}$ ) produced the surface areas of 3479 and 3583 $\mathrm{m}^{2} / \mathrm{g}$ for MOF-5, 1493 and $1578 \mathrm{~m}^{2} / \mathrm{g}$ for ZIF-8, 2004 and $2006 \mathrm{~m}^{2} / \mathrm{g}$ for HUKST-1, and 966 and $1006 \mathrm{~m}^{2} / \mathrm{g}$ for MIL-53. This indicates that the surface areas from DubininAstakhov model are well consistent with the accurate surface areas $(3450,1505,1998$, and $1005 \mathrm{~m}^{2} / \mathrm{g}$ for MOF-5, ZIF-8, HUKST-1, and MIL-53, respectively) obtained from $\mathrm{N}_{2}$ adsorption at $77 \mathrm{~K}$. Using Langmuir model for $\mathrm{C}_{2} \mathrm{H}_{2}$ adsorption isotherms (at 273 and $298 \mathrm{~K}$ ) gave the surface areas as follows: -6860 and $3274 \mathrm{~m}^{2} / \mathrm{g}$ for MOF-5, -2239 and $-1385 \mathrm{~m}^{2} / \mathrm{g}$ for ZIF-8, 1728 and $1548 \mathrm{~m}^{2} / \mathrm{g}$ for HUKST-1, and 833 and $818 \mathrm{~m}^{2} / \mathrm{g}$ for MIL-53. The surface areas for the MOFs were also obtained using BET model for $\mathrm{C}_{2} \mathrm{H}_{2}$ adsorption isotherms (at 273 and $298 \mathrm{~K}$ ), namely, 8588 and $1777 \mathrm{~m}^{2} / \mathrm{g}$ for MOF5, -6918 and -2289 for ZIF-8, 1651 and 1508 for HUKST-1, 779 and 778 for MIL-53. Those indicates that all surface areas of the MOFs from $\mathrm{C}_{2} \mathrm{H}_{2}$ adsorption isotherms with Langmuir and BET models are far from their accurate surface areas. Therefore, one can see that only Dubinin-Astakhov model for $\mathrm{C}_{2} \mathrm{H}_{2}$ adsorption isotherms can produce 
reliable surface areas. Since Langmuir equation is based on a chemical adsorption on uniform surface, the unsuitability of Langmuir model for $\mathrm{C}_{2} \mathrm{H}_{2}$ indicates that $\mathrm{C}_{2} \mathrm{H}_{2}$ on MOFs is not a chemical adsorption on a single type of active sites (please see more discussion in the next section). In contrast, BET model is for physical adsorption that mainly occurs near the condensation point. When the temperature of gas adsorption is much higher than its condensation temperature, the BET model cannot be used for the surface area calculation [48]. In other words, the very low melting point $\left(-80{ }^{\circ} \mathrm{C}\right)$ of $\mathrm{C}_{2} \mathrm{H}_{2}$ makes the BET model unsuitable for its adsorption on MOFs at room temperature. Therefore, only Dubinin-Astakhov equation can be used as a general model for $\mathrm{C}_{2} \mathrm{H}_{2}$ adsorption on MOFs.

\subsection{Evaluation of acetylene adsorption by Dubinin-Astakhov model}

The characteristic energy $(E)$ of $\mathrm{C}_{2} \mathrm{H}_{2}$ adsorption on MOFs was calculated with Dubinin-Astakhov model. The obtained $E$ value decreases in the order: $13.6 \mathrm{~kJ} / \mathrm{mol}$ (HKUST-1) $>10.4 \mathrm{~kJ} / \mathrm{mol}($ MIL-53) $>5.0 \mathrm{~kJ} / \mathrm{mol}($ ZIF-8) $>3.7 \mathrm{~kJ} / \mathrm{mol}($ MOF-5). It was demonstrated that the pore size is inversely proportional to the characteristic energy for physical adsorption of gas molecules on porous materials $[53,54]$. The pore sizes of MOF-5 [49], ZIF-8 [55], HKUST-1 [56], and MIL-53 [57] are 12.94, 11.6, 9, and 7.7

$\AA$, respectively. The correlation of the pore sizes with the characteristic energies generates a linear relationship (except HKUST-1) with a negative slope (Fig. 5a). This indicates that $\mathrm{C}_{2} \mathrm{H}_{2}$ on MOF-5, ZIF-8, and MIL-53 is a typical physical adsorption. 
Furthermore, the adsorption heats were calculated with Clausius-Clapeyron equation. As shown in Fig. 5b, the initial adsorption heats of $\mathrm{C}_{2} \mathrm{H}_{2}$ on HKUST-1, MIL-53, ZIF-8, and MOF-5 are 35.6, 20.3, 15.0, and $13.5 \mathrm{~kJ} / \mathrm{mol}$, respectively. The adsorption heats are linearly proportional to the Dubinin-Astakhov characteristic energies for all MOFs except HKUST-1 (Fig. 5b). The exception of HKUST-1 for the above two linear relationships would be due to $\mathrm{C}_{2} \mathrm{H}_{2}$ chemical adsorption. Different from other MOFs, HKUST-1 possesses open $\mathrm{Cu}^{2+}$ sites, which can be bound by gas molecules to form chemical adsorption [58]. The high adsorption heat of $\mathrm{C}_{2} \mathrm{H}_{2}$ on HKUST-1 originated from a chemical bond between $\mathrm{C}_{2} \mathrm{H}_{2}$ and an open $\mathrm{Cu}^{2+}$ site [31].

\section{Conclusions}

$\mathrm{C}_{2} \mathrm{H}_{2}$ adsorption on MOF-5, ZIF-8, HKUST-1, and MIL-53 were fitted by DubininAstakhov, Langmuir, and BET models. Only Dubinin-Astakhov equation can provide a perfect-fit for all four MOFs. The application of the Dubinin-Astakhov equation to $\mathrm{C}_{2} \mathrm{H}_{2}$ adsorption produced reliable surface areas for MOFs. Furthermore, the relationship between Dubinin-Astakhov characteristic energies and pore sizes revealed that $\mathrm{C}_{2} \mathrm{H}_{2}$ adsorption on MOF-5, ZIF-8, and MIL-53 is a typical physical adsorption, whereas $\mathrm{C}_{2} \mathrm{H}_{2}$ adsorption on HKUST-1 contains a chemical adsorption.

\section{Acknowledgements}

This work was supported by the U.S. National Science Foundation (NSF-CBET-0929207).

\section{References}


[1] Z. Zhang, S. Xiang, B. Chen, CrystEngComm 13 (2011) 5983-5992.

[2] R.B. Getman, Y.S. Bae, C.E. Wilmer, R.Q. Snurr, Chem. Rev. 112 (2012) 703-723.

[3] S.M. Chavan, G.C. Shearer, E. Bloch, S. Bordiga, ChemPhysChem 13 (2012) 445-448.

[4] R. Matsuda, R. Kitaura, S. Kitagawa, Y. Kubota, R.V. Belosludov, T.C. Kobayashi, H. Sakamoto, T. Chiba, M. Takata, Y. Kawazoe, Y. Mita, Nature 436 (2005).238-241.

[5] D.W. Breck, W.G. Eversole, R.M. Milton, T.B. Reed, T.L. Thomas, J. Am. Chem. Soc. 78 (1956) 5963-5972.

[6] B.L. Newalkar, N.V. Choudary, U.T. Turaga, R.P. Vijayalakshmi, P. Kumar, S. Komarneni, T.S.G. Bhat, Micropor. Mesopor. Mater. 65 (2003) 267-276.

[7] C.R. Reid, K.M. Thomas, J. Phys. Chem. B 105 (2001) 10619-10629.

[8] P.K. Thallapally, L. Dobranska, T.R. Gingrich, T.B. Wirsig, L.J. Barbour, J.L. Atwood, Angew. Chem. Int. Ed. 45 (2006) 6506-6509.

[9] S. Lim, H. Kim, N. Selvapalam, K.-J. Kim, S.J. Cho, G. Seo, K. Kim. Angew. Chem. Int. Ed. 47 (2008) 3352-3355.

[10] Y.H. Hu, L. Zhang, Adv. Mater. 22 (2010) E117-E130.

[11] Y.H. Hu, L. Zhang, Phys. Rev. B 81 (2010) 174103.

[12] S.-I. Noro, S. Kitagawa, M. Kondo, K. Seki, Angew. Chem. Int. Ed. 39 (2000) 2081-2084.

[13] J.S. Seo, D. Whang, H. Lee, S.I. Jun, J. Oh, Y.J. Jeon, K. Kim, Nature 404 (2000) 982 986.

[14] B. Li, Y. Zhang, D. Ma, T. Ma, Z. Shi, S. Ma, J. Am. Chem. Soc. 136 (2014) 1202-1205.

[15] O.K. Farha, C.E. Wilmer, I. Eryazici, B.G. Hauser, P.A. Parilla, K. O'Neill, A.A. Sarjeant, S.T. Nguyen, R.Q. Snurr, J.T. Hupp, J. Am. Chem. Soc. 134 (2012) 9860-9863. 
[16] X.C. Huang, Y.Y. Lin, J.P. Zhang, X.M. Chen, Angew. Chem. Int. Ed. 45 (2006) 15571559.

[17] B. Wang, A.P. Côté, H. Furukawa, M. O’Keeffe, O.M. Yaghi, Nature 453 (2008) 207211.

[18] H. Wu, W. Zhou, T. Yildirim, J. Am. Chem. Soc. 129 (2007) 5314-5315.

[19] P. Cheng, Y.H. Hu, J. Phys. Chem. C 118 (2014) 21866-21872.

[20] L. Zhang, Y.H. Hu, J. Phys. Chem. C 115 (2011) 7967-7971.

[21] D. Farrusseng, S. Aguado, C. Pinel, Angew. Chem. Int. Ed. 48 (2009) 7502-7513.

[22] A. Rezk, R. Al-Dadah, S. Mahmoud, A. Elsayed, Appl. Energy 112 (2013) 1025-1031.

[23] L. Pan, D.H. Olson, L.R. Ciemnolonski, R. Heddy, J. Li, Angew. Chem. 118 (2006) 632 635.

[24] Y.-S. Xue, Y. He, S.-B. Ren, Y. Yue, L. Zhou, Y.-Z. Li, H.-B. Du, X.-Z. You, B. Chen, J. Mater. Chem. 22 (2012) 10195-10199.

[25] S. Xiang, W. Zhou, Z. Zhang, M.A. Green, Y. Liu, B. Chen, Angew. Chem. Int. Ed. 49 (2010) 4615-4618.

[26] X.-J. Hou, P. He, H. Li, X. Wang, J. Phys. Chem. C 117 (2013) 2824-2834.

[27] X. Duan, J. Cai, J. Yu, C. Wu, Y. Cui, Y. Yang, G. Qian, Micropor. Mesopor. Mater. 181 (2013) 99-104.

[28] Z. Zhang, S. Xiang, Y.-S. Chen, S. Ma, Y. Lee, T. Phely-Bobin, B. Chen, Inorg. Chem. 49 (2010) 8444-8448.

[29] Z. Zhang, S. Xiang, X. Rao, Q. Zheng, F.R. Fronczek, G. Qian, B. Chen, Chem. Commun. 46 (2010) 7205-7207. 
[30] M. C. Das, H. Xu, S. Xiang, Z. Zhang, H.D. Arman, G. Qian, B. Chen, Chem. Eur. J. 17 (2011) 7817-7822.

[31] S. Xiang, W. Zhou, J.M. Gallegos, Y. Liu, B. Chen, J. Am. Chem. Soc. 131 (2009) 1241512419.

[32] X. Rao, J. Cai, J. Yu, Y. He, C. Wu, W. Zhou, T. Yildirim, B. Chen, G. Qian, Chem. Commun. 49 (2013) 6719-6721.

[33] W. Yang, A.J. Davies, X. Lin, M. Suyetin, R. Matsuda, A.J. Blake, C. Wilson, W. Lewis, J.E. Parker, C.C. Tang, M.W. George, P. Hubberstey, S. Kitagawa, H. Sakamoto, E. Bichoutskaia, N.R. Champness, S. Yang, M. Schröder, Chem. Sci. 3 (2012) 2993-2999.

[34] S.A. Prabhudesai, V.K. Sharma, S. Mitra, R. Mukhopadhyay, Eur. Phys. J. B 86 (2013) 145.

[35] Y. Hu, S. Xiang, W. Zhang, Z. Zhang, L. Wang, J. Bai, B. Chen, Chem. Commun. (2009) $7551-7553$.

[36] Z. Chen, S. Xiang, H.D. Arman, J.U. Mondal, P. Li, D. Zhao, B. Chen, Inorg. Chem. 50 (2011) 3442-3446.

[37] Y. He, Z. Zhang, S. Xiang, F.R. Fronczek, R. Krishna, B. Chen, Chem. Eur. J. 18 (2012) $613-619$.

[38] G. Chen, Z. Zhang, S. Xiang, B. Chen, CrystEngComm 15 (2013) 5232-5235.

[39] M.M. Dubinin, E.D. Zaverina, L.V. Raduahkevich, Zh. Fiz. Khim. 21 (1947) 1351-1362.

[40] M. Polanyi, Trans. Faraday Soc. 28 (1932) 316-333.

[41] M.M. Dubinin, in: P.L. Walker Jr. (Ed.), Chemistry and Physics of Carbon, Marcel Dekker, New York, 1966, pp. 51-120. 
[42] M.M. Dubinin, V.A. Astakhov, L.V. Radushkevich, Physical adsorption of gases and vapors in micropores, progress and membrane science, in: D.A. Cadenhead, J.F. Danielli, M.D. Rosenberg (Eds.), Progress in Surface and Membrane Science, Academic Press, New York, 1975, pp. 1-70.

[43] M.M. Dubinin, V.A. Akstakhov, Izv. Akad. Nauk SSSR, Ser. Khim. 1 (1971) 5-11.

[44] R. Ghosal, D.M. Smith, J. Porous Mater. 3 (1996) 247-255.

[45] S.G. Chen, R.T. Yang, Langmuir 10 (1994) 4244-4249.

[46] E. Poirier, R. Chahine, P. Bénard, L. Lafi, G. Dorval-Douville, P.A. Chandonia, Langmuir $22(2006) 8784-8789$.

[47] T. Siemieniewska, K. Tomkow, J. Kaczmarczyk, A. Albiniak, Y. Grillet, M. Francois, Energy Fuels 4 (1990) 61-70.

[48] Y.H. Hu, E. Ruckenstein, Chem. Phys. Lett. 425 (2006) 306-310.

[49] S.S. Kaye, A. Dailly, O.M. Yaghi, J.R. Long, J. Am. Chem. Soc. 129 (2007) 14176-14177.

[50] S. Brunauer, P.H. Emmett, E. Teller, J. Am. Chem. Soc. 60 (1938) 309-319.

[51] Krista S. Walton and Randall Q. Snurr, J. Am. Chem. Soc. 129 (2007) 8552-8556.

[52] V.B. Lewes, Acetylene: a handbook for the student and manufacturer, Archibald Constable and Co, Westminster, 1900.

[53] F. Stoeckli, L. Ballerini, Fuel 70 (1991) 557-559.

[54] M.M. Dubinin, Carbon 23 (1985) 373-380.

[55] K.S. Park, Z. Ni, A.P. Côté, J.Y. Choi, R. Huang, F.J. Uribe-Romo, H.K. Chae, M. O’Keeffe, O.M. Yaghi, Proc. Natl. Acad. Sci. USA 103 (2006) 10186-10191.

[56] A.Ö. Yazaydın, A.I. Benin, S.A. Faheem, P. Jakubczak, J.J. Low, R.R. Willis, R.Q. Snurr, 
Chem. Mater. 21 (2009) 1425-1430.

[57] T. Loiseau, C. Serre, C. Huguenard, G. Fink, F. Taulelle, M. Henry, T. Bataille, G. Férey, Chem. Eur. J. 10 (2004) 1373-1382.

[58] V.K. Peterson, Y. Liu, C.M. Brown, C.J. Kepert, J. Am. Chem. Soc. 128 (2006) 15578-15579. 


\section{Table 1}

The surface areas obtained from the Langmuir, BET, Dubinin-Astakhov equations at 273 and $298 \mathrm{~K}$ and measured from $\mathrm{N}_{2}$ BET at $77 \mathrm{~K}$.

\begin{tabular}{llllllll}
\hline Sample & \multicolumn{2}{l}{ Langmuir $\left(\mathrm{m}^{2} / \mathrm{g}\right)$} & BET $\left(\mathrm{m}^{2} / \mathrm{g}\right)$ & \multicolumn{2}{l}{$\begin{array}{l}\text { Dubinin-Astakhov } \\
\left(\mathrm{m}^{2} / \mathrm{g}\right)\end{array}$} & $\begin{array}{l}\text { Standard } \\
\text { measurement }\end{array}$ \\
\cline { 2 - 7 } & $273 \mathrm{~K}$ & $298 \mathrm{~K}$ & $273 \mathrm{~K}$ & $298 \mathrm{~K}$ & $273 \mathrm{~K}$ & $298 \mathrm{~K}$ & $\left(\mathrm{~m}^{2} / \mathrm{g}\right)$ \\
\hline MOF-5 & -6860 & 3274 & 8588 & 1777 & 3479 & 3583 & 3450 \\
ZIF-8 & -2239 & -1385 & -6918 & -2289 & 1493 & 1578 & 1505 \\
HKUST-1 & 1728 & 1548 & 1651 & 1508 & 2004 & 2006 & 1998 \\
MIL-53 & 833 & 818 & 779 & 778 & 966 & 1006 & 1005 \\
\hline
\end{tabular}
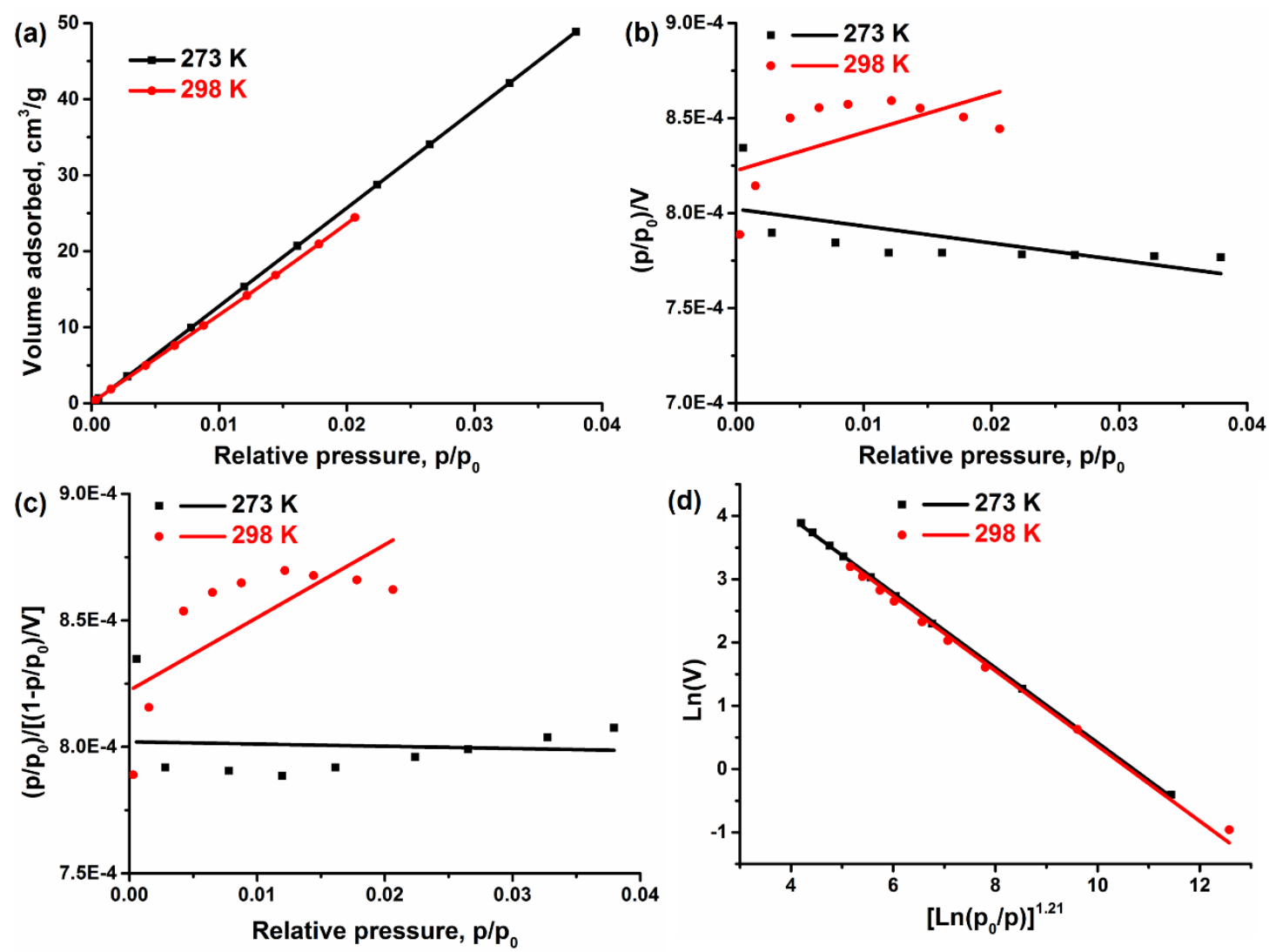

Fig. 1. (a) $\mathrm{C}_{2} \mathrm{H}_{2}$ adsorption isotherms on MOF-5 at 273 and $298 \mathrm{~K}$. Application of the (b) Langmuir, (c) BET, and (d) Dubinin-Astakhov equations to $\mathrm{C}_{2} \mathrm{H}_{2}$ adsorption on MOF-5 at 273 and $298 \mathrm{~K}$ (the squares and circles represent experimental data and the solid lines represent modeling predictions). 

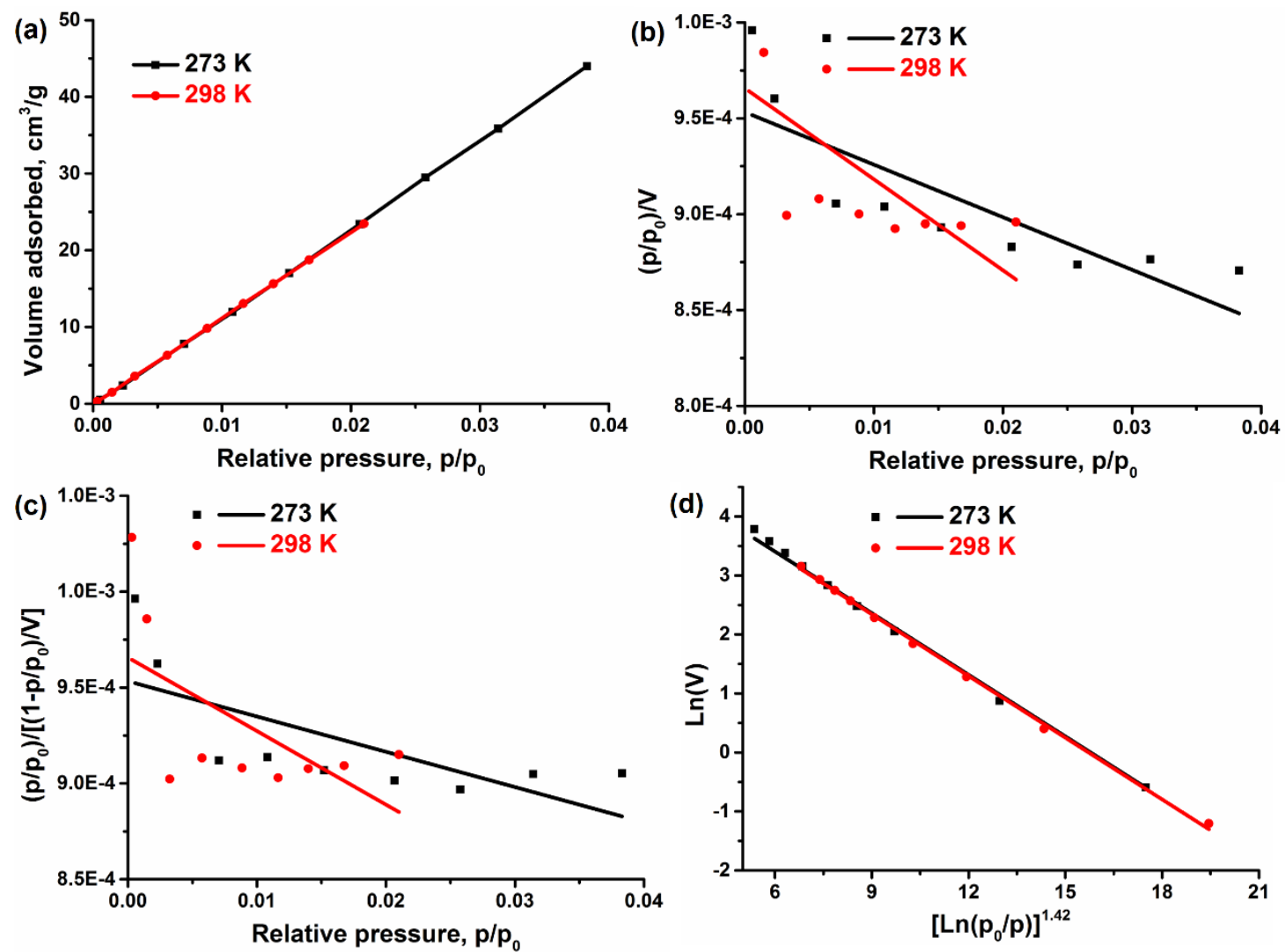

Fig. 2. (a) $\mathrm{C}_{2} \mathrm{H}_{2}$ adsorption isotherms on ZIF-8 at 273 and $298 \mathrm{~K}$. Application of the (b) Langmuir, (c) BET, and (d) Dubinin-Astakhov equations to $\mathrm{C}_{2} \mathrm{H}_{2}$ adsorption on ZIF-8 at 273 and $298 \mathrm{~K}$ (the squares and circles represent experimental data and the solid lines represent modeling predictions). 

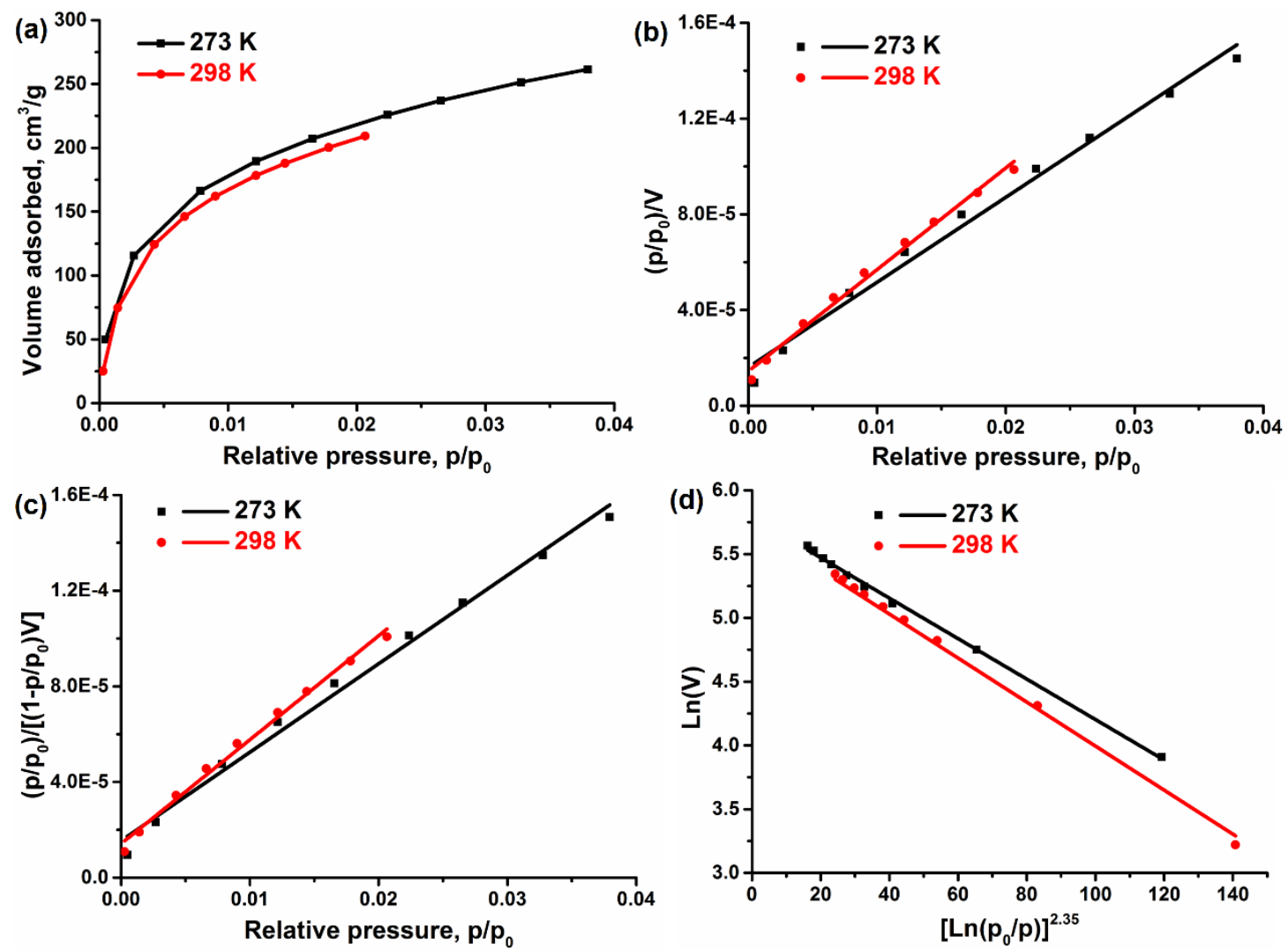

Fig. 3. (a) $\mathrm{C}_{2} \mathrm{H}_{2}$ adsorption isotherms on HKUST-1 at 273 and $298 \mathrm{~K}$. Application of the (b) Langmuir, (c) BET, and (d) Dubinin-Astakhov equations to $\mathrm{C}_{2} \mathrm{H}_{2}$ adsorption on HKUST-1 at 273 and $298 \mathrm{~K}$ (the squares and circles represent experimental data and the solid lines represent modeling predictions). 

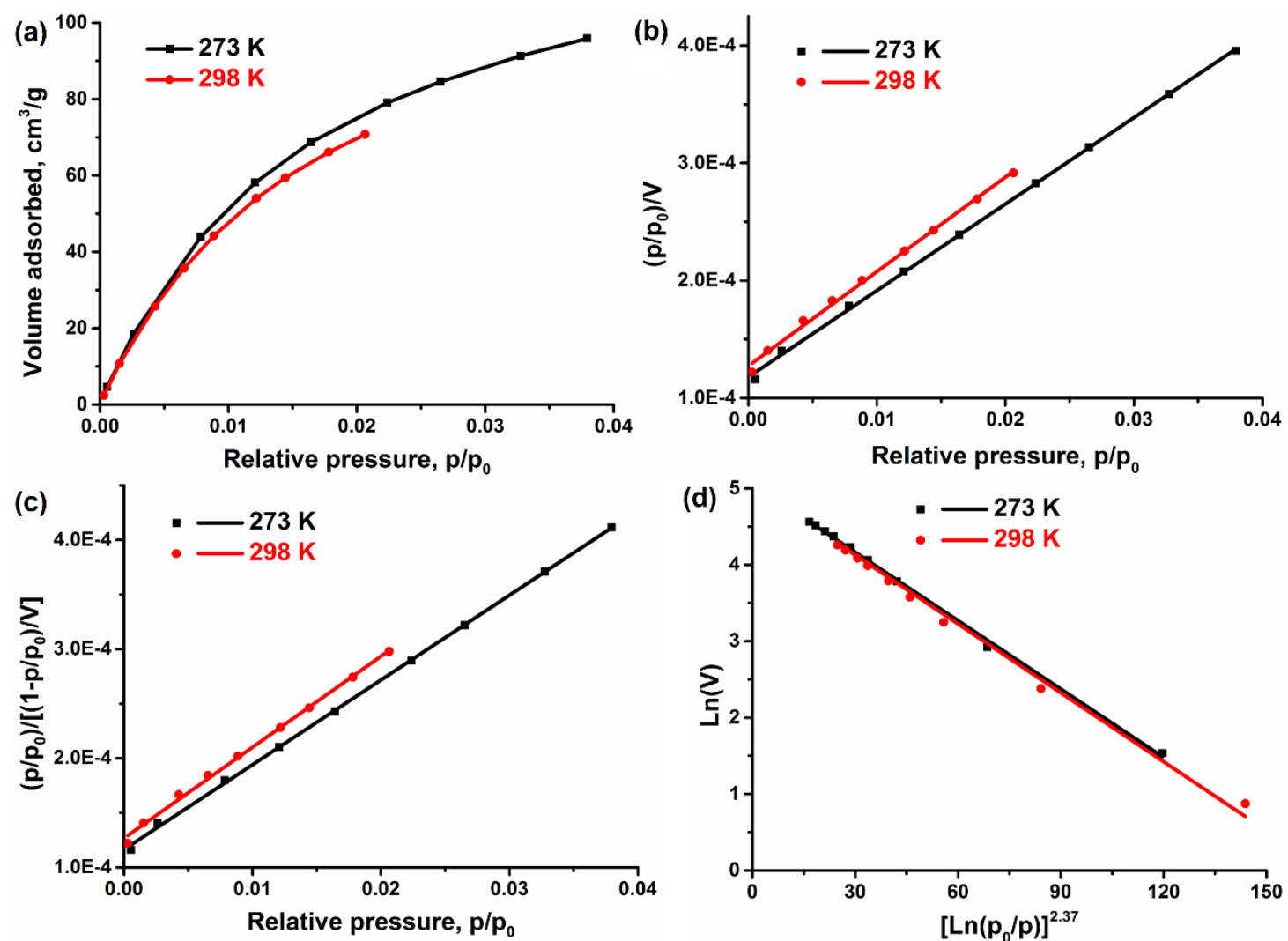

Fig. 4. (a) $\mathrm{C}_{2} \mathrm{H}_{2}$ adsorption isotherms on MIL-53 at 273 and $298 \mathrm{~K}$. Application of the (b) Langmuir, (c) BET, and (d) Dubinin-Astakhov equations to $\mathrm{C}_{2} \mathrm{H}_{2}$ adsorption on MIL-53 at 273 and $298 \mathrm{~K}$ (the squares and circles represent experimental data and the solid lines represent modeling predictions).
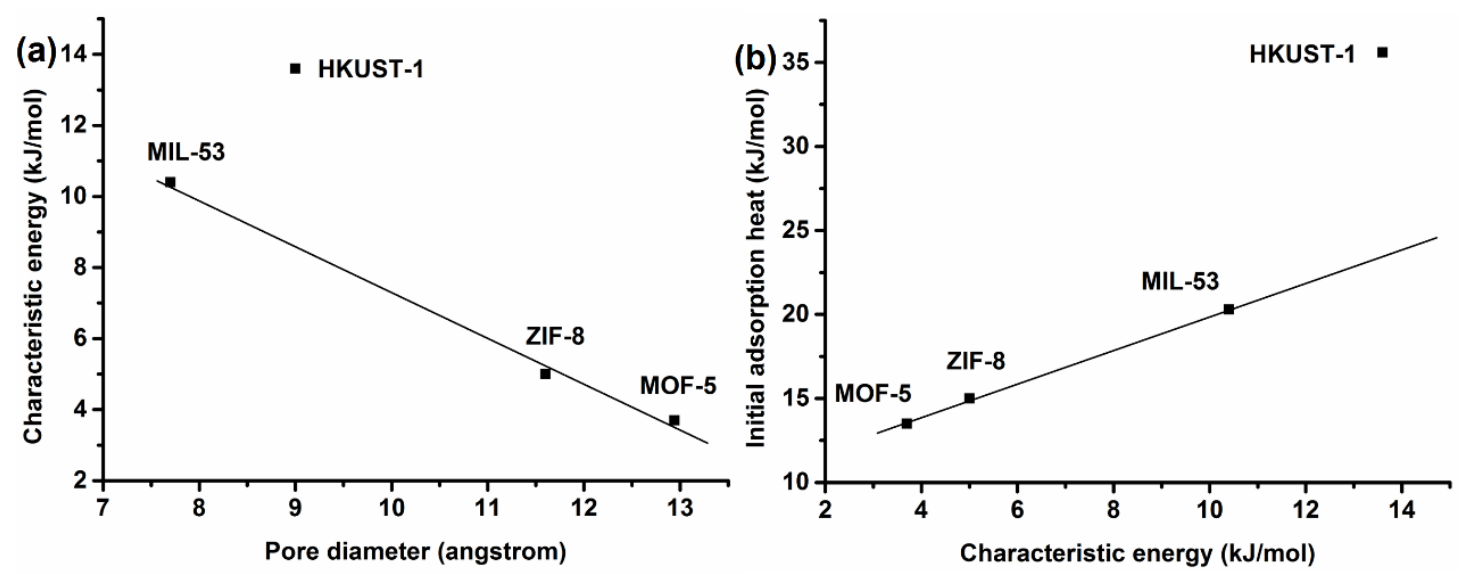

Fig. 5. (a) The correlation of the pore sizes with the characteristic energies on MOFs. (b) The correlation of the characteristic energies with the initial adsorption heats on MOFs. 


\section{Graphical abstract}

It was demonstrated that Dubinin-Astakhov equation can be exploited as a general isotherm model for $\mathrm{C}_{2} \mathrm{H}_{2}$ adsorption on metal-organic frameworks (MOFs), including MOF-5, ZIF-8, HKUST-1, and MIL-53.

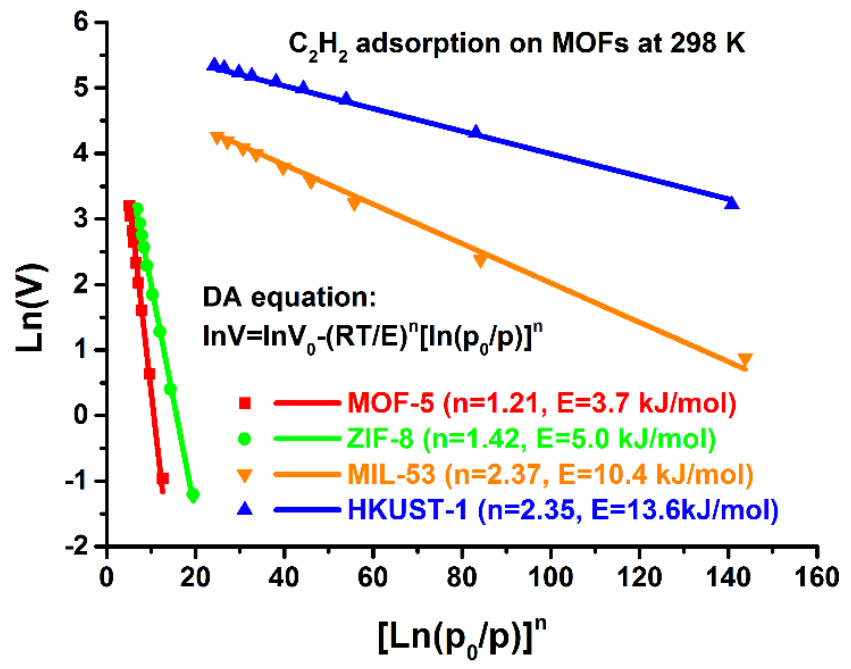

